\title{
Androgen secreting adrenocortical tumours
}

O D Wolthers, F J Cameron, I Scheimberg, J W Honour, P C Hindmarsh, M O Savage, R G Stanhope, C G D Brook

\begin{abstract}
Background-Androgen secreting adrenocortical tumours are rare in children and the determination of their malignant potential can be difficult.

Objectives-To assess the presentation, histology, and clinical behaviour of these tumours.

Setting-Two tertiary referral centres.

Study design-Retrospective analysis of children diagnosed with an androgen secreting adrenocortical tumour between 1976 and 1996.

Patients-Twenty three girls and seven boys aged $0-14$ years.

Results-Pubic hair was observed in all children, clitoromegaly or growth of the phallus in 23 children, acceleration of linear growth in 22 children, and advanced bone age ( $>1.5$ years) in 18 children. Hypersecretion of androgens was detected by assessment of serum androgen concentrations alone in four patients and by 24 hour urine steroid excretion profiles in 22 patients. All 16 tumours measuring $<5 \mathrm{~cm}$ in diameter were benign. Of the tumours measuring $5-9 \mathrm{~cm}$, three were malignant and seven were benign, whereas all four tumours $>10 \mathrm{~cm}$ were malignant. Histological slides were available for reassessment in 25 children. Although mitoses and necrosis were more characteristic of tumours with malignant behaviour, no exclusive histological features of malignancy were seen.

Conclusion-Histological criteria for malignancy are not reliable, whereas tumour size is important in assessing malignant potential.

(Arch Dis Child 1999;80:46-50)
\end{abstract}

Keywords: androgen secreting adrenocortical tumours; malignancy

Diagnosis and management of adrenocortical tumours in children is often problematical. ${ }^{12}$ Experience with these uncommon tumours is limited and most published observations are based on individual cases. ${ }^{3-8}$ They may secrete various steroid hormones including androgens, oestrogens, cortisol, and aldosterone. ${ }^{9}$ Accordingly, patients may present with virilisation, feminisation, hypercortisolism, or hyperaldosteronism, alone or in combination. The majority of these tumours secrete androgens, and it has been suggested that most of them are carcinomas, and that pure virilising adenomas are rare. ${ }^{90}$ Criteria for assessment of the malignant potential of purely virilising adenomas in children have not been established. Our aim was to review our population of children with androgen secreting adrenocortical tumours diagnosed during the last two decades with respect to clinical presentation, markers of androgen hypersecretion, histology, and outcome.

\section{Patients and methods}

We studied, retrospectively, records from two tertiary centres of children aged $0-14$ years with a diagnosis of an androgen secreting adrenocortical tumour made between 1976 and 1996. We collected data on sex, age at presentation, duration of symptoms before diagnosis, clinical features of virilisation, pubertal stages according to Tanner ratings, ${ }^{11}$ height, and bone age performed by the TW2 method. ${ }^{12}$ Acceleration of growth was defined as crossing two or more height centiles. Data on metastases, chemotherapy, and follow up were also collected.

Serum concentrations of dehydroxyepiandrosterone-sulphate (DHEA-S), androstenedione, testosterone, cortisol, 17-hydroxyprogesterone, aldosterone, and oestradiol, and 24 hour urine steroid data were recorded. Furthermore, imaging (computed tomography and magnetic resonance imaging), and histological descriptions were noted. Based on imaging and/or the histopathology description we rated tumour size as small $(<5 \mathrm{~cm}$ in diameter), moderate $(5-9 \mathrm{~cm})$, or large $(>10 \mathrm{~cm}) \cdot{ }^{13}$ The weight of the tumours was also recorded. Slides were provided from the archives of the histopathology departments involved and were reviewed (by IS) for the following features: pleomorphism, mitoses, necrosis, venous and capsular invasion, and fibrous bands. ${ }^{13-17}$

\section{Results}

We identified 32 cases but excluded two with benign tumours because of missing data. Twenty three of the children were girls, seven were boys. At the time of diagnosis, 18 children were $0-4$ years old, 10 were $5-9$ years old, and two were 10-14 years old. The overall age range was $0.4-12.3$ years with a mean of 4.9 .

\section{SYMPTOMS}

The time from the first observation of virilising symptoms to the time of diagnosis was $0.1-2$ (mean 0.6) years. The most frequent sign was pubic hair. Twenty eight children presented with stage III pubic hair, one with stage II, and one with stage V. Clitoromegaly or growth of the phallus was recorded in 23 , acne in 12 , and hirsutism in 10. Cushingoid facies were observed in four children, deepening of the voice in two girls, and gynaecomastia in one boy. 
Table 1 Pathohistology, weight, size, and behaviour of androgen secreting adrenocorticol tumours in 25 children

\begin{tabular}{|c|c|c|c|c|c|c|c|c|c|}
\hline Patient & Pleomorphism & Mitoses & Necrosis & $\begin{array}{l}\text { Venous } \\
\text { invasion }\end{array}$ & $\begin{array}{l}\text { Capsular } \\
\text { invasion }\end{array}$ & $\begin{array}{l}\text { Fibrous } \\
\text { bands }\end{array}$ & Weight & $S i z e^{\star}$ & Behaviour \\
\hline 1 & +++ & + & - & + & - & + & $12 \mathrm{~g}$ & 1 & B \\
\hline 2 & + & + & + & + & - & + & $25 \mathrm{~g}$ & 1 & B \\
\hline 3 & +++ & + & - & + & - & - & $12 \mathrm{~g}$ & 1 & B \\
\hline 4 & ++ & +++ & ++ & ++ & + & +++ & $1200 \mathrm{~g}$ & 3 & $M$ \\
\hline 5 & + & + & - & - & - & - & $21 \mathrm{~g}$ & 2 & B \\
\hline 6 & ++ & + & - & - & - & - & $7 \mathrm{~g}$ & 2 & B \\
\hline 7 & + & + & - & - & - & - & Not stated & 1 & B \\
\hline 8 & + & + & - & - & - & + & Not stated & 2 & B \\
\hline 9 & +++ & + & - & + & + & ++ & Not stated & 1 & B \\
\hline 10 & ++ & + & - & - & - & - & $12 \mathrm{~g}$ & 1 & B \\
\hline 11 & +++ & ++ & ++ & + & + & + & Not stated & 3 & M \\
\hline 12 & ++ & ++ & + & - & - & ++ & Not stated & 2 & $M$ \\
\hline 13 & + & - & - & + & - & - & $39 \mathrm{~g}$ & 2 & B \\
\hline 14 & ++ & +++ & - & - & - & - & Not stated & 1 & B \\
\hline 15 & +++ & +++ & +++ & + & - & + & $95 \mathrm{~g}$ & 2 & B \\
\hline 16 & + & +++ & +++ & + & + & ++ & $173 \mathrm{~g}$ & 2 & M \\
\hline 17 & +++ & ++ & - & - & - & + & $13 \mathrm{~g}$ & 1 & B \\
\hline 18 & ++ & +++ & +++ & + & - & ++ & $164 \mathrm{~g}$ & 2 & M \\
\hline 19 & ++ & ++ & +++ & - & - & +++ & $1400 \mathrm{~g}$ & 3 & M \\
\hline 20 & +++ & +++ & + & + & - & ++ & $189 \mathrm{~g}$ & 3 & M \\
\hline 21 & +++ & + & - & - & + & + & Not stated & 1 & B \\
\hline 22 & ++ & - & - & + & - & - & Not stated & 1 & B \\
\hline 23 & - & - & - & - & - & + & $55 \mathrm{~g}$ & 2 & B \\
\hline 24 & ++ & + & + & - & - & + & $308 \mathrm{~g}$ & 2 & B \\
\hline 25 & ++ & + & - & - & - & ++ & $13 \mathrm{~g}$ & 1 & $\mathrm{~B}$ \\
\hline
\end{tabular}

+ , mild; ++, moderate; +++ , severe.

$\star 1,<5 \mathrm{~cm} ; 2,5-9 \mathrm{~cm} ; 3, \geqslant 10 \mathrm{~cm}$.

$\mathrm{B}$, benign; $\mathrm{M}$, malignant.

GROWTH AND BONE AGE

Acceleration of linear growth was noted in 22 children; growth was normal in three. Bone age assessments were reported in 25 children, showing advances $>1.5$ years in 18 of these children.

\section{BIOCHEMICAL ASSESSMENTS}

Serum concentrations of testosterone, androstenedione, and DHEA-S were available in 22, 10 , and 11 patients, respectively, and were high in 18, six, and 11 of the investigated cases. Serum oestradiol, cortisol, and 17hydroxyprogesterone were assessed in seven, nine, and 13 patients, respectively. Cortisol was high in three patients, otherwise the data were within normal ranges.

Twenty four hour urine steroid excretion rates were assessed in 22 patients. $11 \beta$ Hydroxyandrosterone was the major steroid in nine children, DHEA-S in seven, and androsterone, aetiocholanolone, and 16 $\alpha$-hydroxy-DHEA-S in two children, respectively. The androgen metabolites, androstenetriol $(\mathrm{n}=6)$ and pregnanetriol $(\mathrm{n}=2)$ were also detected.

\section{TUMOUR CHARACTERISTICS}

Nineteen tumours were located in the left adrenal cortex, 10 in the right, and one tumour was found in ectopic adrenocortical tissue in the left iliac fossa (patient 14; table 1).

Twenty five of the 30 histological case slides were retrieved from the histopathology departments. The tumours in the five unretrievable cases were all small and all behaved in a benign way. Of the 25 tumours studied histologically (table 1) seven behaved as malignant. All four large tumours $(\geqslant 10 \mathrm{~cm}$ ) were malignant; two weighed more than $500 \mathrm{~g}$ (patients 4 and 19), one weighed $189 \mathrm{~g}$ (patient 20), and the weight of the other was unknown (patient 11). Three moderate sized tumours $(5-9 \mathrm{~cm})$ weighing
$164 \mathrm{~g}$ and $173 \mathrm{~g}$ (patients 18 and 16, respectively) were malignant. Seven other moderate sized tumours were benign; one of those tumours weighed $308 \mathrm{~g}$ (patient 24). All 16 small tumours $(<5 \mathrm{~cm})$ and all those weighing less than $150 \mathrm{~g}$ were benign. The largest benign tumour (patient 24;308 g) had large areas of haemorrhage, which might have accounted for the excess weight.

Pleomorphism was present in both benign and malignant tumours (fig 1A and D); many benign tumours were extremely pleomorphic, although some lacked pleomorphism (fig 1C). Mitoses tended to be more numerous in malignant tumours, especially abnormal forms, but were not confined to these tumours, with numerous mitoses including abnormal forms being present in benign neoplasms. Large areas of necrosis were more characteristic of malignancy (fig $1 \mathrm{E}$ ), but at least one benign tumour had extensive necrosis (patient 15) and another had large areas of haemorrhage (patient 24). Venous and capsular invasion were found in both benign and malignant tumours (fig $1 \mathrm{~F}$ ) but many had neither of these features. In general, malignant tumours had more fibrous bands, but these were also found in some benign tumours (patients 19 and 25) (fig $1 \mathrm{E}$ and $\mathrm{B}$ ).

TREATMENT AND OUTCOME

All patients had an adrenalectomy, except the child with an ectopic tumour who had the tumour and the ectopic tissue excised. Two children with local tumour growth (patients 11 and 19) had an ipsilateral nephrectomy.

Treatment and outcome data in the seven children with malignant tumours are given in table 2. No signs of recurrent tumour activity were detected in 16 children with small tumours or in seven with moderate tumours during $\geqslant 5$ years $(n=15), 4$ years $(n=3), 2$ 

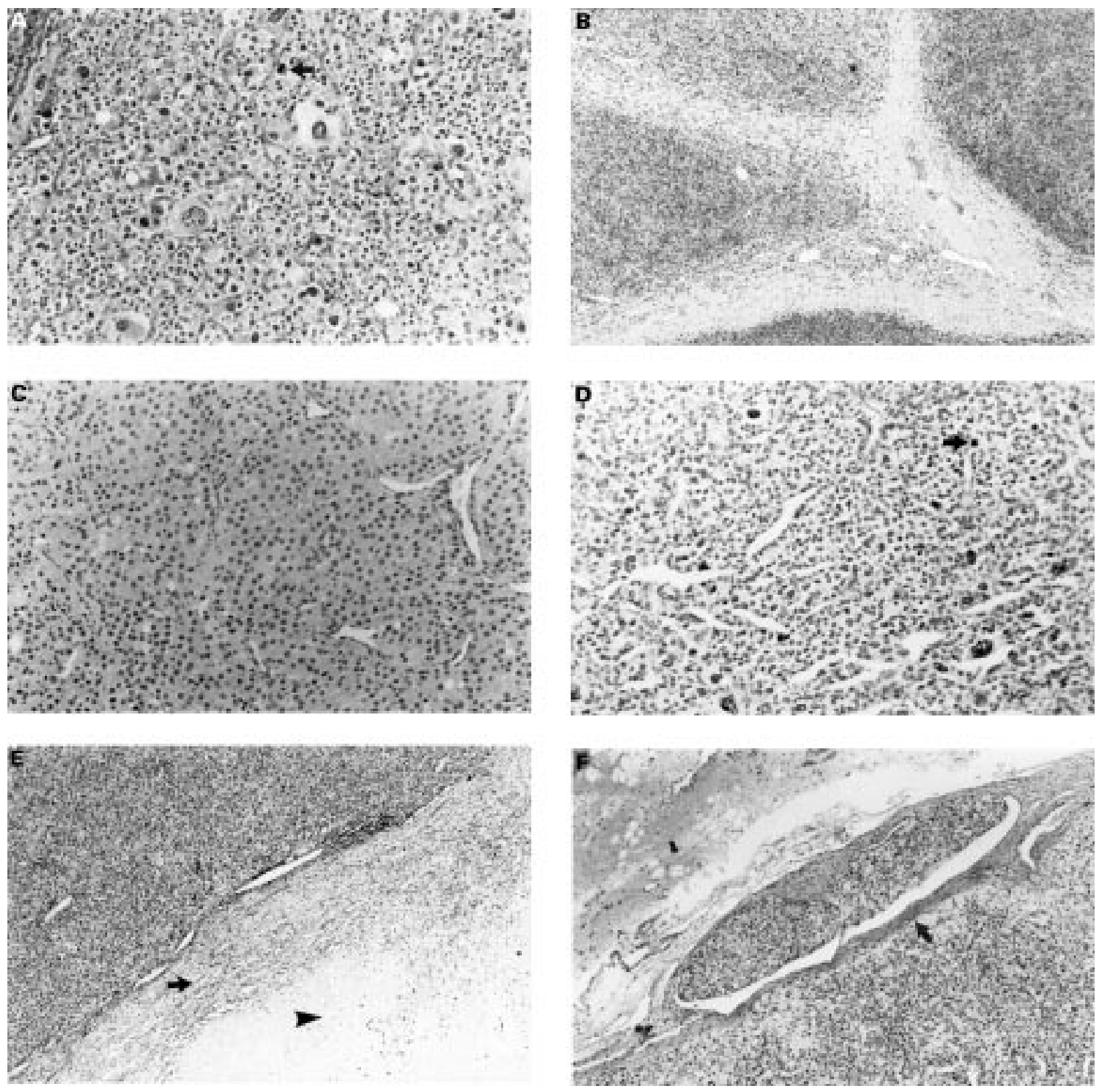

Figure 1 (A) Benign tumour (patient 15) showing marked pleomorphism and mitosis (arrow); note the marked difference between cells, some with gigantic vesicular nuclei. (B) Prominent fibrous bands in a benign tumour (patient 25). (C) A malignant tumour (patient 16) showing lack of pleomorphism. (D) Pleomorphism and abnormal mitoses (arrow) in a malignant tumour (patient 19). (E) Necrosis (arrowhead) and fibrous band (arrow) (patient 19). (F) A malignant tumour (patient 16) showing capsular invasion (arrow).

Table 2 Treatment and outcome in seven children with malignant androgen secreting adrenocortical tumours

\begin{tabular}{|c|c|c|c|}
\hline Patient & Metastases & Treatment & Outcome \\
\hline 4 & $\begin{array}{l}\text { Local tumour growth, hepatic, } \\
\text { and pulmonary metastases aa }\end{array}$ & $\begin{array}{l}\text { o'p-DDD, vincristine cisplatin, } \\
\text { etoposide,cyclophosphamide, } \\
\text { carboplatin }\end{array}$ & Alive 6 months pa \\
\hline 11 & Local tumour growth aa & o'p-DDD & Died 5 months pa \\
\hline 12 & $\begin{array}{l}\text { Local tumour growth and } \\
\text { hepatic metastases } 3.8 \text { years pa }\end{array}$ & o'p-DDD & Died 4.3 years pa \\
\hline 16 & $\begin{array}{l}\text { Hepatic and pulmonary } \\
\text { metastases } 9 \text { months pa }\end{array}$ & $\begin{array}{l}\text { o'p-DDD, carboplatin, excision } \\
\text { of pulmonary metastases }\end{array}$ & Alive 3.6 years pa \\
\hline 18 & $\begin{array}{l}\text { Hepatic and pulmonary } \\
\text { metastases } 10 \text { months pa }\end{array}$ & o'p-DDD & Died 1.8 years pa \\
\hline 19 & $\begin{array}{l}\text { Local tumour growth aa; } \\
\text { pulmonary metastases } 3.8 \text { years } \\
\text { pa }\end{array}$ & None & Alive 4.0 years pa \\
\hline 20 & $\begin{array}{l}\text { Hepatic and pulmonary } \\
\text { metastases } 8 \text { months pa }\end{array}$ & o'p-DDD & Died 1.8 years pa \\
\hline
\end{tabular}

aa, at adrenalectomy; pa, postadrenalectomy; o'p-DDD, 1,1-dichloro-2-(o-chlorophenyl)-2-(pchlorophenyl)-ethane. years $(n=2), 1$ year $(n=2)$, and $<1$ year $(\mathrm{n}=1)$ of follow up.

\section{Discussion}

Adrenocortical tumours comprise less than $0.5 \%$ of tumours in children and represent a small percentage of tumours of the adrenal gland. ${ }^{91819}$ The incidence is reported to vary between 0.3 and 4/1 000000 children below the age of 15 years, and these tumours are more likely to occur in girls than in boys, as is confirmed by our data. ${ }^{320}$ The peak incidence in the present series was under 5 years of age, in accord with previous observations. ${ }^{13561920}$

More than $95 \%$ of adrenocortical tumours in children secrete hormones. ${ }^{1}$ In virilising tumours, clinical symptoms are caused by 
hypersecretion of androgens, with resultant pseudosexual precocity in boys and virilisation in girls. Typically, precocious development of pubic hair is seen, together with tall stature, and acceleration of growth rate and bone maturation. In girls enlargement of the clitoris occurs. In boys growth of the phallus contrasts to prepubertal testicular volumes. However, as indicated from our findings in one boy, pubertal testicular volumes may be seen occasionally. ${ }^{3}$ This might be a result of androgen stimulation of tubular growth or androgen stimulation resulting in true precocious puberty.

The diagnosis of a virilising adrenocortical tumour depends on the detection of raised markers of androgen secretion in combination with imaging. High concentrations of adrenal androgens, especially DHEA-S, are highly suggestive of a tumour. ${ }^{18131720}$ Assessment of steroid metabolites in 24 hour urine is useful for diagnosis, but principally for follow up of the androgen hypersecretory state. ${ }^{20}{ }^{21}$ The most frequently detected raised androgens are $11 \beta$-hydroxyandrosterone and DHEA-S. The urine profile analysis becomes normal after successful surgery, whereas recurrence of abnormal urine steroid profiles suggests recurrent tumour activity. However, adrenocortical tumours might show considerable biochemical heterogeneity, and the steroid excretion pattern may change spontaneously. ${ }^{22}$

Certain morphological criteria of malignancy have been proposed in adrenal tumours in adults. ${ }^{16}$ These include broad fibrous bands, diffuse growth pattern, vascular invasion, widespread tumour necrosis, $>10$ mitoses/ high power field, cellular pleomorphism, and capsular invasion. These criteria have been suggested as less reliable in predicting malignant behaviour in children. ${ }^{20}{ }^{23}$ Furthermore, in the paediatric population, adrenocortical tumours have been considered as predominantly malig-

nant. ${ }^{814202124}$ However, most of the previous reports included tumours with a heterogeneity of hormonal secretion patterns. Our series is the largest population of purely androgen secreting tumours published and the histopathology was uniformly re-evaluated. This might explain why only about a quarter of the patients were diagnosed as having a malignant tumour. Although certain histological features suggest malignancy, such as the presence of numerous mitoses with abnormal forms, widespread necrosis, and broad fibrous bands, these features can also be found in some benign tumours. Paediatric benign tumours, both in our experience and in that of others, ${ }^{14}$ are more likely to show severe pleomorphism and mitoses than adult benign tumours.

In our series, no tumour below $150 \mathrm{~g}$ and less than $5 \mathrm{~cm}$ in diameter behaved in a malignant way. On the other hand, all tumours weighing more than $500 \mathrm{~g}$ and measuring $10 \mathrm{~cm}$ or more were malignant. One benign tumour (patient 24) weighed more than $300 \mathrm{~g}$ and, although it did not have extensive necrosis, it showed large areas of haemorrhage. Another (patient 15) had all the histological features suggestive of malignancy (marked pleomorphism, numerous mitoses with abnormal forms, extensive necrosis, broad fibrous bands, and venous invasion (fig 1B)) but there were no metastases at presentation and no recurrence after five years of follow up. Both these tumours measured $5-9 \mathrm{~cm}$. Thus, the presence of metastases at presentation and tumour weight and/or size seem to be more valuable than histopathology in the assessment of malignant potential. These findings are in accord with previous reports. ${ }^{71315172023}$

The definitive treatment of an adrenocortical tumour is resection. Chemotherapy is not recommended unless hormone concentrations rise and symptoms persist, or there is other evidence of metastases. ${ }^{17}$ The current mainstay of treatment for a malignant tumour is 1,1-dichloro-2-(o-chlorophenyl)-2-(pchlorophenyl)-ethane (o'p-DDD). This agent causes adrenal destruction leading to symptomatic relief. ${ }^{17} 2025$ However, the effect on survival rates seems to be poor, as indicated from our own and other observations. ${ }^{17}$ Trials of other agents such as cisplatin, etoposide, 5-fluorouracil, or vincristine, alone or in combination with mitotane, have not produced convincing results. ${ }^{17} 26$

We conclude that most androgen secreting adrenocortcol tumours in children are benign. Histological criteria for malignancy are not reliable and tumour size is the best indicator of malignant potential. In the future, studies targeting cellular oncogenes and tumour suppressor genes may provide tumour markers useful in the clinical assessment of the malignant potential of androgen secreting tumours in children. ${ }^{17}$ It has been reported that malignant adrenal tumours do not express major histocompatibility complex class II antigens, whereas most benign tumours do, ${ }^{27}$ but it is not yet clear whether this observation is clinically relevant.

1 Chudler RM, Kay R. Adrenocortical carcinoma in children. Urol Clin North Am 1989;16:469-79.

2 Nasir J, Walton C. Adrenal mass with virilisation: importance of endocrine investigation. BMF 1996;313: importanc-3.

3 Burrington JD, Stephen CA. Virilizing tumours of the adrenal gland in childhood: report of eight cases. F Pediatr Surg 1969: 4:291-302.

4 Lee PDK, Winter RJ, Green OC. Virilizing adrenocortical tumours in childhood: eight cases and a review of the literature. Pediatrics 1985;76:437-44.

5 Tsukamoto T, Kumamoto Y, Takahashi A, et al. Adrenocortical carcinoma in a child with specific pedigree of family associated with cancer aggregation. F Urol 1992;147:104-6.

6 Federici S, Galli G, Ceccarelli, et al. Adrenocortical tumours in children: a report of 12 cases. Eur 7 Pediatr Surg 1994;4:21-5.

7 Mendonca BB, Lucon AM, Menezes AV, et al. Clinical, hormonal and pathological findings in a comparative study of drenocortical neoplasms in childhood and adulthood. 7 Urol 1995;154:2004-9.

8 Bergada I, Venara M, Maglio S, et al. Functional adrenal cortical tumours in pediatric patients. Cancer 1996;77:7717.

9 Forest MG. Adrenal steroid excess. In: Brook CGD, ed. Clinical paediatric endocrinology. Oxford, Blackwell Science, 1995:499-535.

10 Korth-Schutz S. Cushing's syndrome and adrenocortical carcinoma in childhood. In: New MI, Levine LS, eds. Adrenal diseases in childhood. Pediatric and adolescent endocrinology. Basel: Karger 1984:185-209.

11 Tanner JM. Growth at adolescence. Oxford, Blackwell, 1962.

12 Tanner JM, Whitehouse RH, Cameron N, Marshall WA, Healy MJR, Goldstein H. Assessment of skeletal maturity and prediction of adult height (TW2 method). London: Academic Press, 1990. 
13 Hough AJ, Hollifield JW, Page DL, Hartmann WH. Prognostic factors in adrenal cortical tumours: a mathematical analysis of clinical and morphological data. Am $\mathcal{F}$ Clin Pathol 1979;72:390-9.

14 Cagle PT, Hough AJ, Pysher J, et al. Comparison of adrenal cortical tumours in children and adults. Cancer 1986;57: 2235-7.

15 Cagle PT, LeFevre M, Gerard-Marchant R, Gubler JP, Chaussain JL, Lemerle J. In: Jumphrey GB, Grindey GB, Dehner LP, Acton RT, Pysker TJ, eds. Adrenal and endocrine tumours in children. Boston: Martinus Nijhoff Publishers, 1983:265-76.

16 Bugg MF, Ribeiro RC, Roberson PK, et al. Correlation of pathologic features with clinical outcome in pediatric adrenocortical neoplasia. Am f Clin Pathol 1994;101:625-9.

17 Latronico AC, Chrousos GP. Extensive personal experience: adrenocortical tumours. F Clin Endocrinol Metab 1997;82: adrenocorti $1317-24$

18 Young JL, Miller RW. Incidence of malignant tumors in US children. F Pediatr 1975;86:254-8.

19 McWhirter WR, Stiller CA, Lennox EL. Carcinomas in childhood. Cancer 1989;63:2242-6.

20 Sandrini R, Ribeiro RC, Delacerda L. Extensive personal experience: childhood adrenocortical tumours. If Clin Endocrinol Metab 1997;82:2027-31.
21 Honour JW, Price DA, Taylor NF, Marsden HB, Grant DB. Steroid biochemistry of virilising adrenal tumours in childhood. Eur f Pediatrics 1984:142:165-9.

22 Halmi KA, Lasciari AD. Conversion of virilization to feminization in a young patient with adrenal cortical carcinoma. Cancer 1971;27:931-5.

23 Ribeiro RC, Sandrini NRS, Schell MJ, Lacerda L, Sambaio GA, Cat I. Adrenocortical carcinoma in children. A study of 40 cases. F Clin Oncol 1990;8:67-74.

24 Gabrilove JL, Seman AT, Sabet R. Virilizing adrenal adenoma with studies on the steroid content of the adrenal venous effluent and a review of the literature. Endocrinol Rev 1981;2:462-70.

25 Haak HR, Hermans J, Velde CJH, et al. Optimal treatment of adrenocortical carcinoma with mitotane: results in a consecutive series of 96 patients. Cancer 1994;69:947-51.

26 Schlumberger M, Ostronoff M, Bellaiche M, Rougier P, Droz JP, Parmentier C. 5- Flourouracil, doxorubicin, and cisplatin regimen in adrenal cortical carcinoma. Cancer 1988;61:1492-4.

27 Marx C, Wolkersdörfer GW, Brown JW, Scherbaum WA, Bornstein SR. MHC class II expression-a new tool to assess dignity in adrenocortical tumours. F Clin Endocrinol Metab 1996;81:4488-91 